\title{
Effect of An Educational Program on Critical Care Nurses Performance regarding Emergency Care for Patients with Pulmonary Embolism
}

\author{
Abdulnasser A. Haza ${ }^{1}$, Faker A. Al-Qubati ${ }^{2}$, Mona A. Mohammed ${ }^{3}$, Mervat A. Abdel-Aziz ${ }^{4} \&$ Mogedda M. $^{2}$ \\ Mehany. \\ 1. Assistance Lecture of Critical Care and Emergency Nursing, Faculty of Medical Sciences, Al-Razi \\ University, Yemen. \\ 2. Professor of a Pulmonologist, Faculty of Medicine and Health Sciences, Sana'a University, Egypt. \\ 3.4.5. Assistant Professor of Critical Care and Emergency Nursing, Faculty of Nursing, Assiut University, Egypt.
}

\begin{abstract}
Background: Pulmonary embolism is the most important emergency in the cardiovascular system with a high rate of mortality without appropriate treatment. Aim: To investigate the effect of an educational program on critical care nurses' performance regarding pulmonary embolism emergency care. A Quasi-experimental design was utilized in this study. This study was carried out in the medical, surgical and emergency Intensive Care Unit at Al-Thawra Modern General Hospital Authority in Sanaa - Yemen. The sample of this study consisted of 75 nurses' for implementing the program. Tools utilized for data collection were the nursing questionnaire and observation checklist. The results There were statistically significant differences $(\mathrm{P}<0.000)$ in the total nurses' knowledge scores regarding emergency care for a patient with pulmonary embolism, pre-implementation of the program compared with the immediately post-implementation and post three months follow up. There were statistically significant differences $(\mathrm{P}<0.000)$ in total nurses' practice scores regarding emergency care for patient with pulmonary embolism pre-implementation compared with the immediately post-implementation and post three months follow up. Conclusion: there was a statistically significant difference between the nurse knowledge and practice in pre/post and follow up implementing of the educational program.
\end{abstract}

\section{Keywords: Emergency Care, Educational Program \& Performance.}

\section{Introduction}

Acute pulmonary embolism is the most serious clinical presentation of venous thromboembolism with fatal pulmonary embolism being a common cause of sudden death, usually resulting from a complication of deep venous thrombosis (Morrone \& Morrone, 2018). Acute pulmonary embolism is the third most common cardiovascular disease after myocardial infarction and cerebrovascular accident (stroke) (Huang et al. 2017).

The diagnosis of pulmonary embolism is difficult, and it may be overlooked because it does not emerge as a specific clinical condition. Furthermore, in recent years, advances in diagnostic methods have also increased the frequency of diagnosis of pulmonary embolism. The mortality rate in patients with pulmonary embolism who cannot be diagnosed reaches $30 \%$; this rate may be reduced to $3 \%$ when diagnosed and treated appropriately. In the majority of cases, the source of thrombus is in the deep veins of the lower extremities, especially the common femoral, superficial, femoral, and popliteal pelvic veins (Karaaslan, Celik, Cagliyan, \& Demir, 2018). Staff development programs include orientation, internship, in-service courses, conferences, seminars, journal clubs, programmed learning, and independent study. The ultimate aim of staff development is to improve patient care by upgrading the services rendered. In addition, the individual nurse acquires new knowledge and improving their practice. Also, the professional growth and development fostered by the educational program by improving the staff member's chances for promotion (Clement, 2015). Nurses can play a major role in vein thromboembolism prevention if well educated and empowered to change hospital culture. Improving nurses' level of knowledge undoubtedly leads to an improvement in the delivery of patient care. Appropriately, trained nurses are skilled in assessing the risk of vein thromboembolism in their clients and ensuring prophylactic measures are in place for those clients who are particularly vulnerable to developing vein thromboembolism. Even in the absence of a medical practitioner, the nurses can initiate appropriate mechanical measures (Ali \& Hassan, 2016). Significance of the Study

Emergency and intensive care nurses can play a major role in pulmonary embolism emergency care, if welleducated and empowered to change hospital culture. Nurses should be involved in establishing protocols for pulmonary embolism management and prevention and in ensuring their implementation. 
According to the patients' records in Al-Thawra Modern General Hospital Authority in Sanaa Yemen through 2018, it was found that there (350) cases of respiratory patients were admitted to intensive care units and the majority of patients have a susceptibility to deep venous thrombosis or pulmonary embolism complicated. Therefore, for these reasons, there is a clear need to effective educate nurses with regard to emergency pulmonary embolism care.

\section{The Aim of the Study}

The aim of the study is to evaluate the effect of an educational program on critical care nurses' performance regarding emergency care for patients with pulmonary embolism.

\section{Research Hypothesis}

To fulfill the aim of this study, the following research hypotheses were formulated:

1. Intensive care and emergency nurses' knowledge regarding the emergency care of patients with pulmonary embolism will be improved post educational program implementation and after three months later than pre educational program implementation.

2. Intensive care and emergency nurses' practice regarding care of the patients with pulmonary embolism in the emergency stage will be improved post educational program implementation and after three months later than pre educational program implementation.

3. A positive correlation existed between nurses' knowledge and practice scores after the application of the educational program.

\section{Subject \& Method}

Research design

A quasi-Experimental design (one group pretest \& posttest) was utilized in this study.

\section{Sample}

A convenience sample of all nurses working in selected sitting and having more than one-year clinical experience about 75 nurses were included in the study.

\section{Setting}

The study was conducted in the medical ICU, surgical ICU and emergency ICU at Al-Thawra Modern General Hospital Authority in Sanaa Yemen.

\section{Study tools}

Data pertinent to the study were collected, utilizing the following two tools:

Tool (I): Knowledge assessment tool

It was constructed by the researcher after reviewing relevant literature (Hinkle \& Cheever, 2017; Morton \& Fontaine, 2017, Urden et al., 2014). It was written in simple Arabic language for assessing nurses' knowledge regarding pulmonary embolism emergency care (pre/immediately post \& post three months program implementation). It included two parts:

Part (A)

Demographic characteristics of nurses such as age, marital status, qualification, years of experience and attendance of previous training about emergency care for patients with pulmonary embolism.

Part (B)

Nurses' knowledge about the care of patients with pulmonary embolism in the emergency stage, which included 22 questions related to the following information:

- Nurse's knowledge in relation to the concept of pulmonary embolism. It was divided into (14) questions as (anatomy and physiology of the respiratory system, definition, causes, risk factors, pathophysiology. signs/symptoms, diagnosis medical management, complications and side effects of pulmonary embolism treatment).

- Nurse's knowledge in relation to emergency nursing management for pulmonary embolism. It was divided into (8) questions.

Scoring system for knowledge: each correct answer scored one grade and score zero for an incorrect response. The total score level for the questionnaire was 78 scores. The total level of knowledge was categorized as follows: satisfactory level for a value equal to or more than $75 \%(\geq 56$ scores) or unsatisfactory level for a value less than $75 \%$ less than 56 scores).

Tool (II): Practice assessment tool by using an observation checklist:

This sheet used in pre/ immediately post and 3 months post the program implementation. The observational checklist sheet was constructed after reviewing related literature (Hinkle \& Cheever, 2017, Wilkinson et al., 2016, Burton \& Ludwig 2015). This checklist was developed and modified by the researcher to assess nurse's practice about nursing care for a patient with pulmonary embolism during the emergency stage by nursing management. The tool covered all the steps of the procedure of nursing care for a patient with pulmonary embolism. The observational checklist comprised of 164 steps as follows:

a. Respiratory system assessment which including 19 steps.

b. Chest pain intervention which including 14 steps.

c. Oxygen therapy procedure which including 16 steps. 
d. Arterial blood gases which including 24 steps.

e. Endotracheal tube intubation procedure which including 32 steps.

f. Cardiac monitoring procedure which including 21 steps.

g. Pulse oximetry procedure which including 13 steps.

h. Intensive spirometer procedure which including 13 steps.

i. Deep breathing exercise procedure which including 12 steps.

Scoring system for nurse's practice: it was scored by giving two scores if the step procedure was done correctly, one score if the step was done incorrect and zero if the step was not done with total scores of 328 , then it was categorized as satisfactory level for value equal to or more than $75 \%(\geq 246$ scores $)$ or unsatisfactory level less than $75 \%$ ( $<246$ scores).

\section{Method}

The study was conducted on three phases (preparatory phase implementation phase and evaluation):

\section{Preparatory phase}

- An official permission to proceed with the proposed study was obtained from the head of the medical, surgical and emergency intensive care unit department as well as the hospital nursing director after explaining the aim and nature of the study.

- The tools were developed by the researcher based on the previous assessment of nurses' knowledge and practices. Available resources and reviews of relevant literature (Morton \& Fontaine, 2018; Hinkle \& Cheever, 2017; Wilkinson et al. 2016; Burton \& Ludwig 2015; Urden et al. 2014).

- Content validity: the tools were tested for content related validity by a jury of 5 specialists in the field of critical care nursing and critical care medicine from Assiut University, and the necessary modifications were done.

- Reliability: knowledge and practice about pulmonary embolism emergency care were tested by (Cronbach's Alpha it was <0.95) for its, internal consistency Reliability for the observation checklist was tested also by (Cronbach's Alpha it was $<0.91$ ).

- A pilot study carried out before starting of data collection to test the feasibility and the clarity of the study tools on 8 nurses (10\%) of the study group, the analysis of the pilot study define the modification required in the tool used, and the necessary modification was done prior to data collection. The studied subjects were excluded from the actual study.
Description of the Educational program

The aim of this program was enriching critical care and emergency nurses with knowledge and practices regarding the care of patients with pulmonary embolism in the emergency stage. The program was devolved and translated into Arabic by researchers based on related literature. The educational program has been implemented in nine sessions:

$\checkmark$ Four theoretical sessions about the following:

1. The duration of each session was 30 minutes.

2. Recognize the definition, causes, and risk factors for pulmonary embolism.

3. Describe pathophysiology, classifications and signs/symptoms for pulmonary embolism.

4. Explain diagnosis, medical management and complications for pulmonary embolism.

5. Identify nursing emergency care for patients with pulmonary embolism.

$\checkmark$ Five clinical sessions about the following:

1. Assessing the technique of the respiratory system (30 minutes).

2. Analyzing arterial blood gas technique and pulse oximetry procedure (30 minutes).

3. Performing cardiac monitoring and chest pain intervention (30 minutes).

4. Performing an oxygen therapy procedure and endotracheal tube intubation (30 minutes).

5. Demonstrating intensive spirometer procedure and deep breathing exercise technique (30 minutes).

- Ethical considerations: An approval was obtained from the local ethical committee and the study was followed by the common ethical principle in clinical research. Written informed consent was obtained from each nurse after an explanation of the study purpose. Anonymity and confidentiality were assured through coding of all data. Critical care nurses were assured that they could withdraw from the study without any rationale at any time.

\section{Implementing phase}

- Data of the current study were collected from February 2018 to 30 July 2019.

- The researcher approached the critical care nurses, five days a week at two shifts (morning and evening) daily.

- The total sample was divided into15 subgroups consisted of 5 nurses for each session.

- Nurses were interviewed individually to establish rapport, explain the purpose and nature of the study, obtaining the written consent, their needs/expectations, discuss the outline of the program, and regulate the next visit and the best way for content. Then, the personal characteristics and knowledge assessment questionnaire about 
pulmonary embolism emergency care (too I). observational checklist for pulmonary embolism emergency care (tool II) was filled out before starting the implementation of the program as a baseline assessment.

- Each theoretical session was carried out in class to include all nurses. All the topics were presented in the form of PowerPoint programs and posters as needed.

- Theoretical sessions started with discussion (10 minutes) to assess nurse's feedback of knowledge about related topics then the researcher started to explain the session content. After the session break time was given to them, (10 minutes $)$ followed by a discussion to assess the nurses' level of understanding and feedback (10 minutes).

- Every session was started first with discussion to assess nurse's feedback about the procedure (5 minutes) then the training phase about the definition, indication, frequency of pulmonary embolism, and technique of the procedure (20 minutes).

- The researcher provided teaching material as videos about the procedure to help nurses during demonstrating it. Videos were presented before and after the demonstration time.

- Each clinical session was repeated more than once on the same day and in the other day to be sure that every nurse reached an accurate skills level of the procedure.

- All nurses included in the study group demonstrated the procedure once or more under the supervision of the researcher in the lab to ensure correct performance and identify the weak points.

- Each nurse of all studied groups obtained a copy of the educational program in Arabic and an English language is a form of a booklet that included all theoretical and practical content.

- The educational aids to explain the topics included hand out, posters and clinical videos for a demonstration of the care provided.

- An open channel communication was achieved between researcher and nurses to ensure understanding answer any question and verify the information and practical skills given.

- The observational checklist was used during data collection to evaluate the nursing level of skills in providing care for patients with pulmonary embolism and to ensure nurses' performance skills until the competency level.

- Each group takes one-week training in ICU so that evaluation of the nurse's skills started from the second week of every group for postimplementation and follow up after three months.

\section{Evaluation phase}

The evaluation of knowledge and practice were done three times as preprogram implementation, immediately post-program implementation and follow up evaluation after a three-month implementation program by using the questionnaire sheet and observation checklist sheet. The nurse who passed $75 \%$ and more of the questionnaire sheet and observation checklist sheet correctly was consider satisfactory but who passed less than $75 \%$ was considered unsatisfactory.

\section{Statistical Analysis}

Data were collected and analyzed by computer program SPSS, version 21. (SPSS Inc., Chicago, USA). Data expressed as mean, standard deviation, number, and percentage. A paired sample t-test is used to significance determine the numeric variable. The chi-square test and ANOVA test are used to determine significance for the non-parametric variable. Also correlation by Pearson correlation. A probability level of 0.05 was adopted as a level of significance for testing the research hypothesis. Statistically significant differences were considered when the P-value was $\leq 0.05$. 


\section{Results}

Table (1): Distribution of studied critical care nurses according to their characteristics $($ No. $=75)$.

\begin{tabular}{|c|c|c|}
\hline \multirow{2}{*}{ Demographical characteristics } & \multicolumn{2}{|c|}{ Frequency } \\
\hline & No. & $\%$ \\
\hline \multicolumn{3}{|l|}{ Age: } \\
\hline - Less than 25yrs & 25 & 33.3 \\
\hline - $\quad 25<30 y r s$ & 35 & 46.7 \\
\hline - $30<35 y r s$ & 12 & 16 \\
\hline - $\quad$ More than 35 & 3 & 4 \\
\hline Mean \pm SD (range) & \multicolumn{2}{|c|}{$26.39 \pm 3.63(20-38)$} \\
\hline \multicolumn{3}{|l|}{ Gender: } \\
\hline • Male & 30 & 40 \\
\hline - $\quad$ Female & 45 & 60 \\
\hline \multicolumn{3}{|l|}{ Education level: } \\
\hline - Diploma nurse & 54 & 72 \\
\hline - $\quad$ Bachelors nurse & 21 & 28 \\
\hline \multicolumn{3}{|l|}{ Years of experience: } \\
\hline$\bullet \quad \leq 2 \mathrm{yrs}$ & 25 & 33.3 \\
\hline - $3-6 y r s$ & 29 & 38.7 \\
\hline - 7 - 10yrs & 17 & 22.7 \\
\hline - $\quad$ More than 10yrs & 4 & 5.3 \\
\hline Mean \pm SD & \multicolumn{2}{|c|}{$4.63 \pm 3.28(1-15)$} \\
\hline \multicolumn{3}{|l|}{ Attendance of previous training about P.E } \\
\hline$\bullet \quad$ Yes & 63 & 84 \\
\hline - $\quad$ No & 12 & 16 \\
\hline \multicolumn{3}{|l|}{ ICU setting: } \\
\hline$\bullet \quad$ Medical ICU & 20 & 26.7 \\
\hline - $\quad$ Surgical ICU & 20 & 26.7 \\
\hline - $\quad$ Emergency ICU & 35 & 46.7 \\
\hline
\end{tabular}

ICU: Intensive care unit.

P.E: Pulmonary embolism.

Table (2): Comparison of the mean score of the studied critical care nurses' knowledge during three tests pre the implementation of the program post and after 3 months $(n=75)$.

\begin{tabular}{|c|c|c|c|c|c|c|c|}
\hline \multirow{2}{*}{ Nursing knowledge } & \multirow{2}{*}{$\begin{array}{c}\begin{array}{c}\text { Pre- } \\
\text { implementat } \\
\text { ion test }\end{array} \\
\text { Mean } \pm \text { SD }\end{array}$} & \multirow{2}{*}{$\begin{array}{c}\begin{array}{c}\text { Immediately } \\
\text { post- } \\
\text { implementation } \\
\text { test }\end{array} \\
\text { Mean } \pm \text { SD }\end{array}$} & \multirow{2}{*}{$\begin{array}{c}3 \text { months } \\
\text { post- } \\
\text { implementatio } \\
n \text { test } \\
\text { Mean } \pm \text { SD }\end{array}$} & \multicolumn{4}{|c|}{ Compression } \\
\hline & & & & $\mathbf{P 1}$ & $\mathbf{P 2}$ & $\mathbf{P 3}$ & P.value \\
\hline Anatomy \& physiology & $3.88 \pm 1.36$ & $7.55 \pm 1.13$ & $5.63 \pm 1.14$ & $<0.001 * *$ & $\begin{array}{c}<0.001 * \\
*\end{array}$ & $\begin{array}{c}<0.001 * \\
*\end{array}$ & $\begin{array}{c}0.001^{*} \\
*\end{array}$ \\
\hline Definition of P.E. & $0.47 \pm 0.50$ & $0.95 \pm 0.23$ & $0.81 \pm 0.39$ & $<0.001^{* *}$ & $\begin{array}{c}<0.001^{*} \\
*\end{array}$ & $0.012 *$ & $\begin{array}{c}<0.001^{*} \\
*\end{array}$ \\
\hline Causes of P.E. & $0.25 \pm 0.44$ & $0.75 \pm 0.44$ & $0.59 \pm 0.50$ & $<0.001 * *$ & $\begin{array}{c}<0.001 * \\
*\end{array}$ & $0.038 *$ & $\begin{array}{c}<0.001 * \\
*\end{array}$ \\
\hline Types of P.E. & $0.44 \pm 0.5$ & $0.80 \pm 0.4$ & $0.56 \pm 0.50$ & $<0.001 * *$ & $\begin{array}{c}<0.001 * \\
*\end{array}$ & $\begin{array}{c}<0.001 * \\
*\end{array}$ & $\begin{array}{c}<0.001^{*} \\
*\end{array}$ \\
\hline Pathophysiology of P.E. & $0.56 \pm 0.86$ & $1.39 \pm 0.77$ & $1.05 \pm 0.75$ & $<0.001 * *$ & $\begin{array}{c}<0.001 * \\
*\end{array}$ & $0.008 *$ & $\begin{array}{c}<0.001^{*} \\
*\end{array}$ \\
\hline Risk factor of P.E. & $0.45 \pm 0.50$ & $0.75 \pm 0.44$ & $0.55 \pm 0.50$ & $<0.001 * *$ & $0.010 *$ & $<0.010^{*}$ & $\begin{array}{c}<0.001 * \\
*\end{array}$ \\
\hline $\begin{array}{l}\text { Signs \& symptom of } \\
\text { P.E. }\end{array}$ & $0.52 \pm 0.66$ & $1.48 \pm 0.64$ & $1.15 \pm 0.63$ & $<0.001 * *$ & $\begin{array}{c}<0.001 * \\
*\end{array}$ & $<0.002 *$ & $\begin{array}{c}<0.001 * \\
*\end{array}$ \\
\hline
\end{tabular}


Haza et al.,

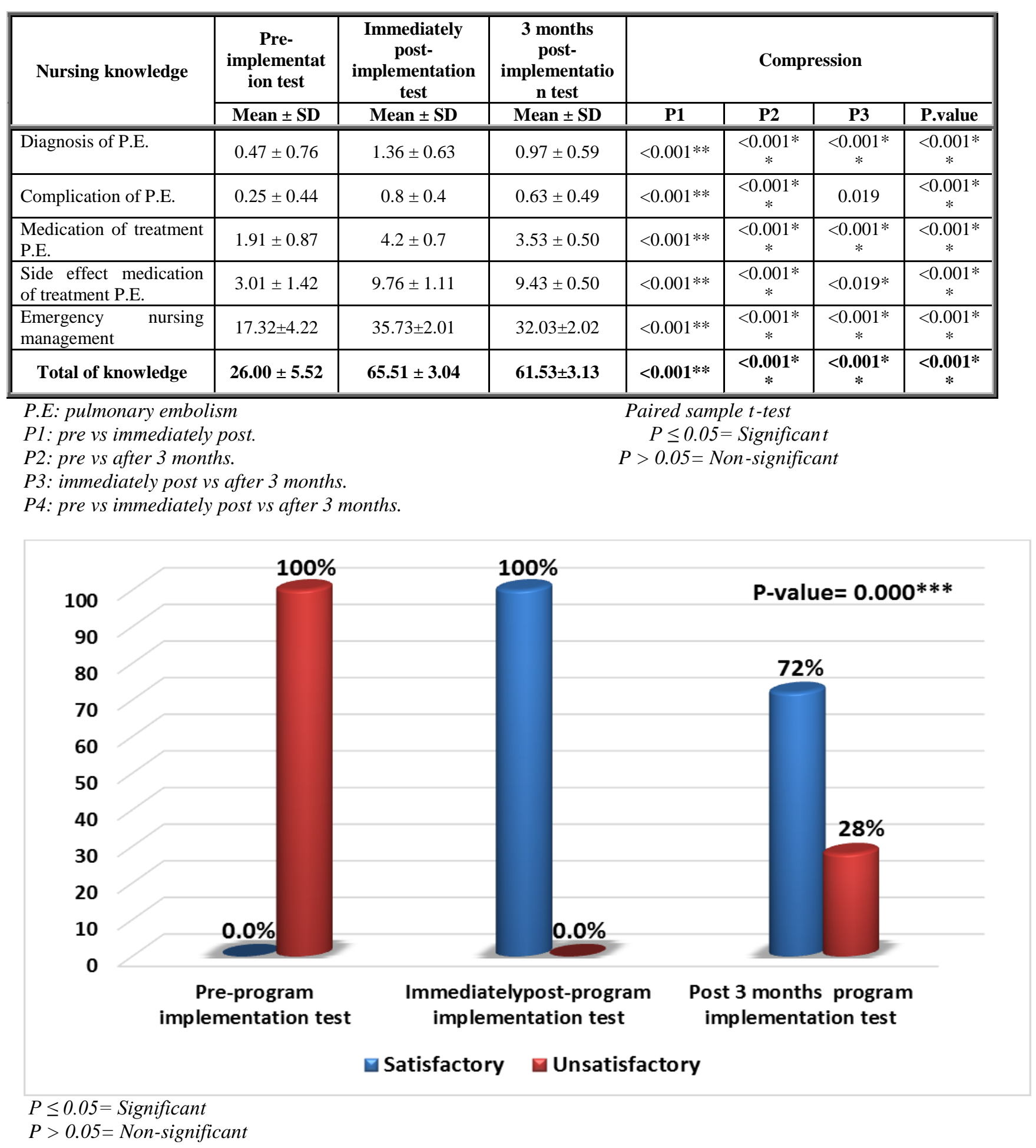

Fig. (1): Distribution of the studied critical care nurses' total knowledge level during the three tests for the education program implementation (pre, immediately post and after 3 months later) $(n=75)$. 
Table (3): Comparison of subtotal mean score the studied critical care nurses practice during the three tests (pre, immediately post and after 3 months later) of education program implementing $(n=75)$.

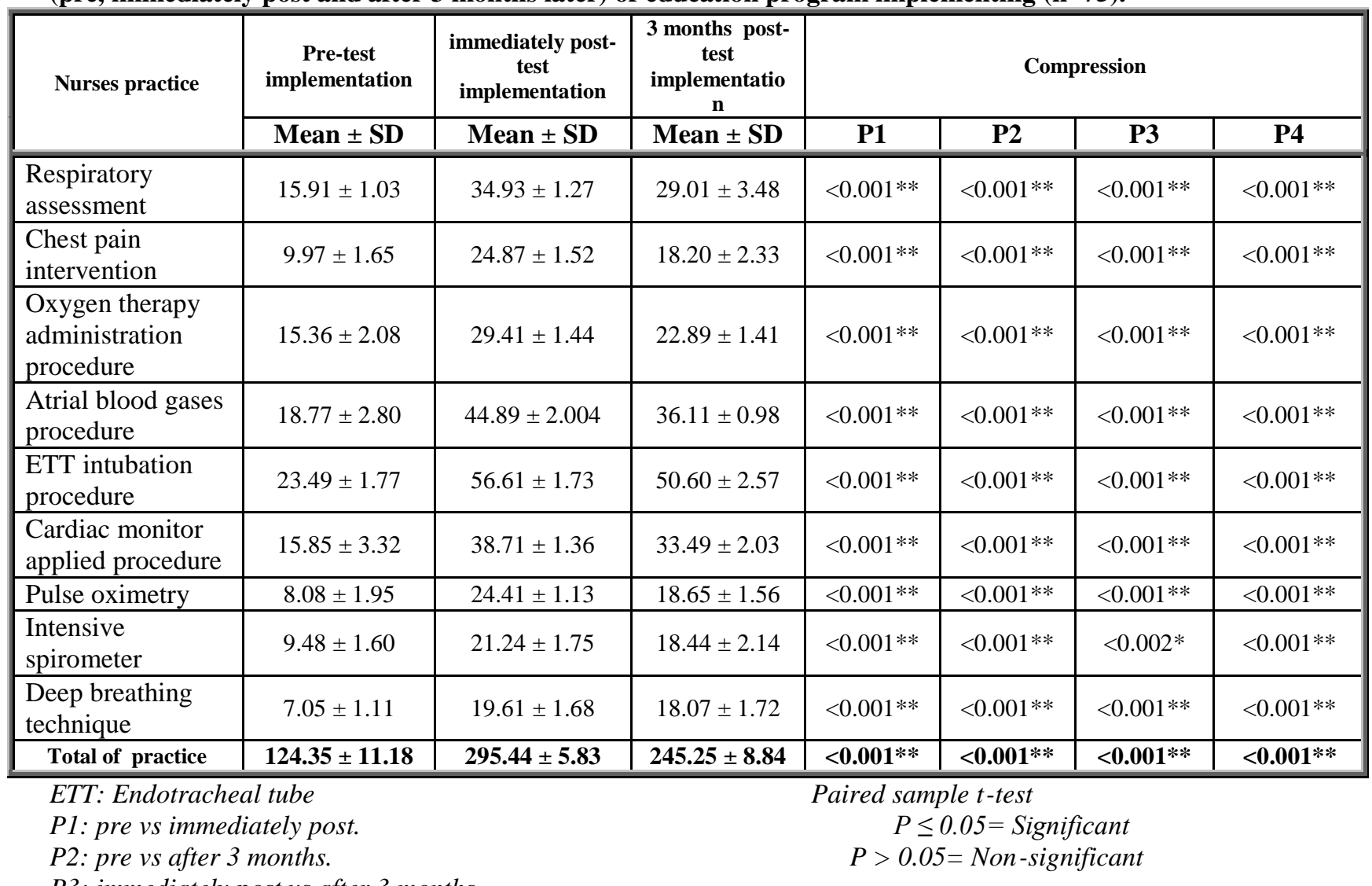

P3: immediately post vs after 3 months.

P4: pre vs immediately post $v$ s after 3 months.

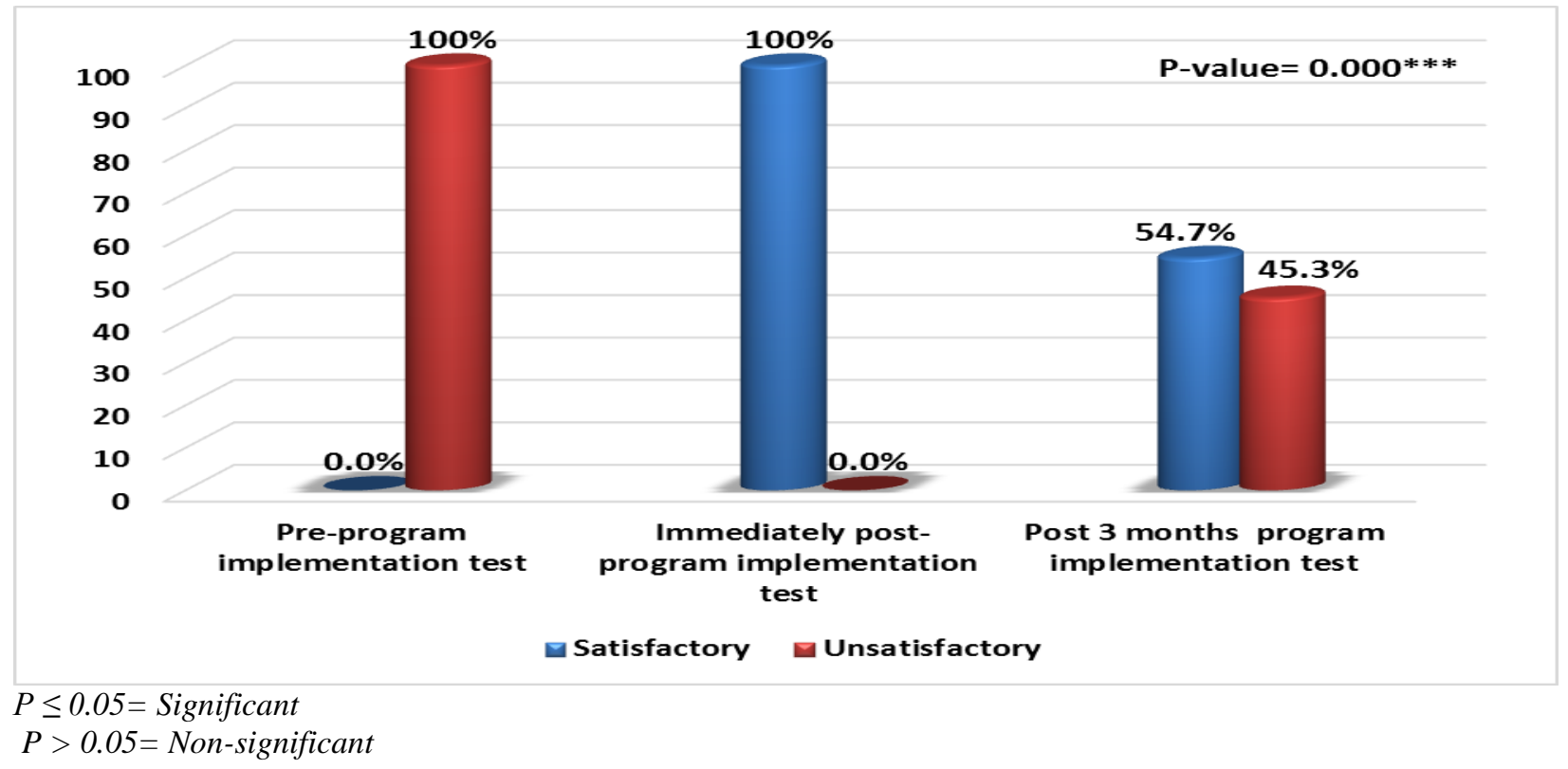

Fig. (2): Distribution of the studied critical care nurses total practice level during the three tests (pre, immediately post and after 3 months later) education program implementing $(n=75)$. 
Table (4): Relationship between studied critical care nurses' total knowledge score and demographic data during the three tests of education program implementation $(n=75)$.

\begin{tabular}{|c|c|c|c|}
\hline \multirow{3}{*}{ Demographic data } & \multicolumn{3}{|c|}{ Total knowledge level } \\
\hline & $\begin{array}{c}\text { Pre-implementation } \\
\text { test }\end{array}$ & $\begin{array}{l}\text { immediately post- } \\
\text { implementation test }\end{array}$ & $\begin{array}{c}3 \text { months post- } \\
\text { implementation test }\end{array}$ \\
\hline & Mean \pm SD & Mean \pm SD & Mean \pm SD \\
\hline \multicolumn{4}{|l|}{ ICU setting: } \\
\hline - $\mathrm{MICU}$ & $26.30 \pm 6.03$ & $65.50 \pm 2.26$ & $61.85 \pm 2.39$ \\
\hline - $\mathrm{SICU}$ & $25.60 \pm 6.34$ & $65.75 \pm 3.01$ & $61.85 \pm 2.78$ \\
\hline - ERICU & $26.06 \pm 4.83$ & $65.37 \pm 3.48$ & $61.46 \pm 3.48$ \\
\hline $\begin{array}{r}\text { P.value } \\
\end{array}$ & $\mathbf{0 . 0 8 2}$ & 0.908 & 0.856 \\
\hline \multicolumn{4}{|l|}{ Age: } \\
\hline - Less than 25yrs & $26.20 \pm 5.77$ & $65.84 \pm 2.88$ & $61.92 \pm 2.67$ \\
\hline - $25<30 y r s$ & $25.91 \pm 5.32$ & $65.40 \pm 2.73$ & $61.63 \pm 2.88$ \\
\hline - $30<35 \mathrm{yrs}$ & $26.00 \pm 6.45$ & $64.83 \pm 3.88$ & $60.92 \pm 3.87$ \\
\hline - More than 35yrs & $25.33 \pm 3.79$ & $66.67 \pm 5.13$ & $63.00 \pm 5.00$ \\
\hline $\begin{array}{r}\text { P.value } \\
\end{array}$ & 0.994 & $\mathbf{0 . 7 2 0}$ & 0.686 \\
\hline \multicolumn{4}{|l|}{ Gender: } \\
\hline - Male & $26.13 \pm 5.57$ & $65.90 \pm 3.04$ & $62.03 \pm 2.70$ \\
\hline - Female & $25.91 \pm 5.54$ & $65.24 \pm 3.04$ & $61.42 \pm 3.20$ \\
\hline P.value & 0.866 & 0.363 & 0.392 \\
\hline \multicolumn{4}{|l|}{ Education level: } \\
\hline - Diploma nurse & $24.89 \pm 5.16$ & $65.20 \pm 2.92$ & $61.37 \pm 2.90$ \\
\hline - Baccrulureate nurse & $28.86 \pm 5.48$ & $66.29 \pm 3.27$ & $62.43 \pm 3.20$ \\
\hline $\begin{array}{r}\text { P.value } \\
\end{array}$ & 0.004* & 0.168 & 0.173 \\
\hline \multicolumn{4}{|l|}{ Years of experience: } \\
\hline$\bullet \leq 2 \mathrm{yrs}$ & $25.80 \pm 6.03$ & $65.12 \pm 2.86$ & $61.04 \pm 2.82$ \\
\hline - 3 - 6yrs & $25.41 \pm 5.08$ & $66.31 \pm 2.88$ & $62.55 \pm 2.67$ \\
\hline - 7 - 10yrs & $26.41 \pm 5.39$ & $64.47 \pm 3.01$ & $60.76 \pm 3.19$ \\
\hline - $\quad$ More than 10yrs & $29.75 \pm 6.40$ & $66.50 \pm 4.66$ & $63.00 \pm 4.55$ \\
\hline $\begin{array}{r}\text { P.value } \\
\end{array}$ & 0.520 & 0.184 & 0.114 \\
\hline \multicolumn{4}{|l|}{ Educational training: } \\
\hline - Yes & $26.25 \pm 4.79$ & $65.42 \pm 4.36$ & $61.58 \pm 4.60$ \\
\hline - No & $25.95 \pm 5.68$ & $65.52 \pm 2.76$ & $61.68 \pm 2.65$ \\
\hline P.value & 0.862 & 0.912 & 0.917 \\
\hline
\end{tabular}

Table (5): Relationship between studied critical care nurses' total practice score and demographic data during the three tests of education program implementation $(n=75)$.

\begin{tabular}{|c|c|c|c|}
\hline \multirow{3}{*}{ Demographic data } & \multicolumn{3}{|c|}{ Total practice level } \\
\hline & $\begin{array}{c}\text { Pre-implementation } \\
\text { test }\end{array}$ & $\begin{array}{l}\text { immediately post- } \\
\text { implementation test }\end{array}$ & $\begin{array}{l}3 \text { months post- } \\
\text { implementation test }\end{array}$ \\
\hline & Mean \pm SD & Mean \pm SD & Mean \pm SD \\
\hline \multicolumn{4}{|l|}{ ICU setting: } \\
\hline - $\mathrm{MICU}$ & $126.00 \pm 8.69$ & $294.85 \pm 6.05$ & $249.25 \pm 9.55$ \\
\hline - SICU & $124.15 \pm 12.60$ & $294.85 \pm 5.88$ & $242.65 \pm 8.34$ \\
\hline - ERICU & $123.51 \pm 10.78$ & $296.11 \pm 5.79$ & $244.46 \pm 8.14$ \\
\hline P.value & 0.732 & 0.651 & $0.045 *$ \\
\hline
\end{tabular}




\begin{tabular}{|c|c|c|c|}
\hline \multirow{3}{*}{ Demographic data } & \multicolumn{3}{|c|}{ Total practice level } \\
\hline & $\begin{array}{c}\text { Pre-implementation } \\
\text { test }\end{array}$ & $\begin{array}{l}\text { immediately post- } \\
\text { implementation test }\end{array}$ & $\begin{array}{c}3 \text { months post- } \\
\text { implementation test }\end{array}$ \\
\hline & Mean \pm SD & Mean \pm SD & Mean \pm SD \\
\hline \multicolumn{4}{|l|}{ Age: } \\
\hline - Less than 25yrs & $120.52 \pm 8.50$ & $295.08 \pm 6.77$ & $243.72 \pm 8.58$ \\
\hline - $25<30 \mathrm{yrs}$ & $125.00 \pm 11.70$ & $295.20 \pm 5.54$ & $245.14 \pm 9.64$ \\
\hline - $30<35 \mathrm{yrs}$ & $131.50 \pm 11.45$ & $297.08 \pm 5.25$ & $249.33 \pm 7.13$ \\
\hline - More than 35yrs & $120.00 \pm 13.45$ & $294.67 \pm 4.16$ & $243.00 \pm 3.46$ \\
\hline $\begin{array}{l}\text { P.value } \\
\end{array}$ & 0.035* & $\begin{array}{l}0.770 \\
\end{array}$ & 0.324 \\
\hline \multicolumn{4}{|l|}{ Gender: } \\
\hline - Male & $123.60 \pm 10.79$ & $295.97 \pm 6.23$ & $245.43 \pm 9.21$ \\
\hline - Female & $124.84 \pm 11.52$ & $295.09 \pm 5.60$ & $245.13 \pm 8.69$ \\
\hline P.value & 0.640 & 0.527 & 0.887 \\
\hline \multicolumn{4}{|l|}{ Education level: } \\
\hline - Diploma nurse & $119.43 \pm 8.86$ & $293.43 \pm 4.97$ & $242.04 \pm 7.66$ \\
\hline - Baccrulureate nurse & $137.00 \pm 4.55$ & $300.62 \pm 4.63$ & $253.52 \pm 5.82$ \\
\hline $\begin{array}{c}\text { P.value } \\
\end{array}$ & $<0.001 * * *$ & $<0.001 * * *$ & $<0.001 * * *$ \\
\hline \multicolumn{4}{|l|}{ Years of experience: } \\
\hline - $\leq 2 \mathrm{yrs}$ & $117.52 \pm 8.08$ & $293.60 \pm 6.28$ & $243.12 \pm 10.09$ \\
\hline - 3-6yrs & $122.00 \pm 9.35$ & $295.45 \pm 5.53$ & $244.24 \pm 7.62$ \\
\hline - $7-10 \mathrm{yrs}$ & $136.06 \pm 8.21$ & $298.53 \pm 4.94$ & $249.94 \pm 7.47$ \\
\hline - More than 10yrs & $134.25 \pm 5.74$ & $293.75 \pm 4.79$ & $246.00 \pm 9.967$ \\
\hline $\begin{array}{l}\text { P.value } \\
\end{array}$ & $<0.001 * * *$ & $<0.052 *$ & 0.081 \\
\hline \multicolumn{4}{|l|}{ Educational training: } \\
\hline - Yes & $133.25 \pm 10.41$ & $297.33 \pm 6.61$ & $249.25 \pm 10.35$ \\
\hline - $\mathrm{No}$ & $122.65 \pm 10.56$ & $295.08 \pm 5.66$ & $244.49 \pm 8.40$ \\
\hline P.value & $<0.002 *$ & 0.082 & 0.088 \\
\hline
\end{tabular}

Table (6): Correlation between total knowledge score $\&$ total practice score during the three tests of education program implementation $(n=75)$.

\begin{tabular}{|c|c|c|c|c|c|c|}
\hline \multirow{4}{*}{ Total practice score } & \multicolumn{5}{|c|}{ Total knowledge score } \\
\cline { 2 - 7 } & \multicolumn{2}{|c|}{ Pre- implementation test } & \multicolumn{2}{|c|}{$\begin{array}{c}\text { Immediately post- } \\
\text { implementation test }\end{array}$} & $\begin{array}{c}\text { 3 months post- } \\
\text { implementation test }\end{array}$ \\
\cline { 2 - 7 } & $\mathbf{R}$ & $\mathbf{P}$ & $\mathbf{R}$ & $\mathbf{P}$ & $\mathbf{R}$ & $\mathbf{P}$ \\
\cline { 2 - 7 } & 0.564 & 0.000 & 0.976 & 0.000 & 0.612 & 0.000 \\
\hline
\end{tabular}

This table (1): Demonstrated that the studied sample consists of 75 nurses (20 were from the medical intensive care unit, 20 from the surgical intensive care unit and 35 from the emergency intensive care unit). It shows that $46.7 \%$ of nurse's age group was from 25 and less than 30 years of age, females were $60 \%$, while $72 \%$ had diploma degree, $38.7 \%$ had (from 3 to less than 6) years of experience, $84 \%$ of nurses were not previously attended training courses about pulmonary embolism.
Table (2): This table shows compression of the mean score of the studied critical care nurses' knowledge regarding the care of patients with pulmonary embolism during pre/post and post 3 months after the implementation of the educational program. There were statistically significant differences (P-value $<0.001$ ) between the mean score of nurses' knowledge pre/post and post 3 months after the implementation of the program regarding the care of the study group for pulmonary embolism. 
Figure (1): Shows that all nurses of intensive care units obtained score of less than $75 \%$ preimplementation of the program and reached a score of equal to or more than $75 \%$ immediately postprogram implementation. Three months later after program implementation, 54 nurses obtained score more than or equal to $75 \%$, while 21 nurses obtained score less than $75 \%$. However. Nurses' knowledge of level shows statistically significant differences between pre, immediately post-program and 3 months later with ( $\mathrm{p}$-value $<0.001)$.

Table (3): This table shows compression of mean score of the studied critical care nurses practice regarding care of patients with pulmonary embolism during pre/ immediately post and post 3 months after the implementation of the education program with statistically significance differences with (P-value $<0.001$ ) between mean score of practice pre/ immediately post and post 3 months after the implementation of the program regarding the care of patients with pulmonary embolism.

Figure (2): Shows that all nurses of intensive care units obtained score of less than $75 \%$ preimplementation of the program and reached a score of equal to more than $75 \%$ immediately post-program implementation. Three months later after program implementation, 41 nurses obtained score more than or equal to $75 \%$, while 34 nurses obtained score less than $75 \%$. However. The practice level shows differences between pre, immediately post-program and 3 months later with statistically significant differences ( $p$-value <0.001).

Table (4): This table shows that there is no statistically significant association between nurses' in ICU setting, age, gender, years of experience, educational level training and their mean of knowledge concerning care of patients with pulmonary embolism at (pretest, immediately postand 3 months post) educational program follow up with (p-value < 0.05). However, there is statistically significant association between nurses' level of education and their mean of knowledge concerning pulmonary embolism care at (pretest) before the educational program with ( $\mathrm{p}$-value $<0.004)$. While, there are no statistically significant differences between nurses' level of education and their mean of knowledge concerning pulmonary embolism care at (immediately post, 3 months post) educational program implementation.

Table (5): Clarify that age and educational training courses showed statistically significant association with nurse practice through pretest of the implementation of the training program with ( $p$-value $<0.035,0.002$ respectively). In addition, education level and years of experience showed statistically significant association with nurse practice through pretest, immediate post and after 3 months from the implementation of the training program with all knowledge items with $(\mathrm{P}=0.001$,$) . Moreover, years of$ experience was a statistically significant association with nurses' mean of practice through pretest and immediately post-implementation of the training program with ( $\mathrm{p}$ value $=0.001,<0.052 *$ respectively). In addition, ICU setting showed statistically significant association with nurse mean of practice through post 3 months after the implementation of the training program with ( $\mathrm{p}$-value $<0.045)$.

Table (6): Shows that there was a positive relationship between pretest knowledge score and total pretest practice, immediately posttest knowledge and immediately posttest practice, three months posttest knowledge score and three months posttest practice score with $(\mathrm{r}=0.564,0.976,0.612$ respectively) with statistical significant differences as (p-value $=0.000)$.

\section{Discussion}

Pulmonary embolism is the most important emergency in the cardiovascular system with a high rate of mortality without appropriate treatment (Karaaslan et al., 2018). Pulmonary embolism occurs when an embolus breaks off a thrombus (blood clot) in a vein and occludes blood vessels of the pulmonary artery tree. (Huisman et al., 2018).

To evaluate the effect of an educational programs on emergency staff nurses' performance toward the care of patients with pulmonary embolism at the emergency care stage.

The present study as shown in reveal that the nearly to half of the nurses age in the study sample were within ( 25 to less than 30 ) years old, this is due to the fact that most of the old nurses has left the hospital to look for other job opportunities because of the war and the failure to pay salary regularly, and replace them with volunteers. This results supported by Abdul-hamza \& Aziz, (2017) who mentioned that most of his study samples were within (25-30) years old. Concerning the nurses' gender, most of the nurses in the study sample were female $(60 \%)$ these results supported by AL-Jumaily \& Khudur, (2019) who mentioned that most of his study sample was female. Moreover, these results are in an agreement with Sage et al., (2008) who reported that the studied sample had a higher percentage of knowledge of nurses who were from the female group.

In regard to the level of education, most of the nurses in the study sample had diploma degree in nursing and working in the intensive care unit, these results agree with Shehab, (2018) who reported that there were majority of studied nurses had secondary 
diploma, while only (10\%) had bachelor degree in nursing. In the same line, Hassan \& Hassan, (2013) mentioned that most of his study sample was from the nursing institute.

Regarding years' of experience, the mean nursing experience years was $4.63 \pm 3.28$. These results disagree with, Chen et al., (2018) who reported that the mean nursing experience was between $8.96 \pm 7.37$ years.

Regarding nurses' training course attendance, the present study showed that all nurses had not attend any previous training courses about nursing care standards for preventing pulmonary embolism. This finding is supported by El Enein et al., (2012) who documented that the majority of the studied nurses hadn't attended any previous training program.

The current study presented that, the nurses' knowledge before the implementation of the program generally was unsatisfactory. This might be related to the fact that the majority of them hold a nursing diploma and all of the nursing books are written in English and they are learning in Arabic. In addition, another cause for a lack of knowledge is that most of them were not receiving any previous training about respiratory care. These findings are supported by Eskander et al., (2013) who found a statistically significant association between nurses' level of knowledge in the post-intervention program compared with the pre-intervention.

In this respect, Jagannathan (2015) revealed in his study report a significant increase in the post-test knowledge scores after structured teaching program. The structured teaching program is one of the effective methods in increasing knowledge regarding the prevention of deep vein thrombosis among nurses. Moreover, the result is in agreement with the study done by Hammod \& Mohammed, (2016) who reported that the program has a positive effect on improving the knowledge of nurses in ICU which indicated the difference between the pretest and posttest of the program. The findings of the study are in the same line with Khalil (2018) who reported that most of the critical care nurses did not apply nonpharmacological managing pain intervention practices with their patients in pain. The approaches which used by a few nurses were only changing position and the use of some comfort devices.

On comparison of pre-test and post knowledge scores by using paired " $t$ " test, the study result shows that there is a significant enhancement in the overall knowledge score of participants regarding the care of patients with pulmonary embolism. It shows that they need to have a basic training to enhance their knowledge regarding emergency care for pulmonary embolism. These findings agree with Lee et al.,
(2014) who found interesting results related to RNs' self-reported vein thromboembolism knowledge and vein thromboembolism risk assessment practices. It is noteworthy that approximately $30 \%$ of participating hospital RNs reported their overall knowledge of vein thromboembolism risk assessment was fair or poor and $31 \%$ reported that they seldom completed VTE risk assessment in their patients. Moreover, this result agree with those of Ali \& Hassan (2016) who showed that posttest knowledge was higher than pretest knowledge scores.

In addition, these findings were in agreement with the study of Antony et al., (2016) who in their study assessed knowledge and self-reported clinical practice on prevention of deep vein thrombosis among staff nurses working in critical care units as all of them had unsatisfactory knowledge on prevention of DVT among hospitalized patients.

The implementation of the educational program had a great effect on nurse's knowledge. This was proved by the high statistical significant differences in all tested items of knowledge before and after implementing the program. The result in agreement with Jaralnabi et al., (2017) who reported a statistically significant difference between the mean pre and post-test scores of nurses' knowledge after the educational program. In addition, this result was supported by Gaston (2013) who reported that the number of nurses who correctly identified who a VTE risk assessment should be performed for all adult admissions, increased by $23 \%$ following the education session.

The present study showed that the majority of nurses mean score in pre-implementation of the program less than those of the post-implementation the practice score with a highly statistically significant relation regarding pulmonary embolism care. This might be due to the absence of a training program, booklet and stander for care inside each unit during the period of program implementation. In the same line with Khalil (2018) who reported that this might be related to many factors as nursing workload, lack of availability of assessment tools, lack of education on assessment tools, lack of familiarity with tools, lack of protocols and guidelines management and no designing area for charting.

This is agree with Mohammed et al., (2018) who showed that the post means the practice score of nurses exposed to an educational program was higher than their pre mean practice score. Moreover, in the same line AbdEInaeem, (2015) found that nurses who received a previous training obtained a high mean score with a statistically significant difference before and after the teaching program. 
These findings are supported by Mitoma \& Yamauchi (2018) who reported that skills related to the physical assessment of the respiratory and cardiovascular systems, showed the effect of an educational program on the nurses' practice of these skills.

The present study shows that there were no statistically significant differences between total knowledge score and demographic characteristic the nurses nearly in all items. It indicate that there was no effect of demographic characteristic of the nurses' data on teaching program regarding to knowledge. This result is agreement with Kaur \& Charan (2018) who reported that no statistically significant association was found between post-test practice score with selected socio-demographic variables- age, sex, years of experience and in-service program which were found to be with non-significant at $\mathrm{p}$ value $<0.05$. In the same line Al-husaunawy (2015) who found that there was no significant differences between knowledge of nurses' and their age, sex and years of experience.

The present study showed that there was a significant association between years of experience and total practice score through all the study periods. The result of the present study agreed with Eskander et al., (2013) who found positive correlations between mean practice scores and nurses years of experience.

The present study showed that significant relation was found between the level of education and total practice score through all the study periods, this means that registered nurses might have good readiness for learning and practicing new things as well their awareness about the continuing education. This result is agreement with Mohammed (2017) who showed that there was a statistically significant difference association between the nurse practice and level of education in all phases of program implementation.

As regarding relations between practice and previous training. This result revealed that the nurses who received previous training obtained high mean scores with the statistical significant difference before the teaching program. It might be attributed to the fact that the skill was retained easily. These findings supported by (AbdEInaeem, 2015) who found that nurses receiving previous training obtained a high mean score with the statistically significant difference before implementing the teaching program.

As regarding to the relationship between knowledge and practice, this study found that there was a positive correlation between nurse's knowledge and practice scores. This reflects the importance of integration between theory and practice. In the same line El-sayedead et al., (2016) \& Das \& Sahoo
(2014) who found that a positive significant correlation between nurses' knowledge and practice related to deep vein thrombosis pre and postimplementation of the education program. Moreover, Khalil et al., (2018) reported a significant correlation between critical care nurses' knowledge and practice regarding the life-threatening diseases.

Finally, the program had achieved its objectives by improving the knowledge and practice of the critical care nurse for effective identification and management of care of patients with pulmonary embolism.

\section{Conclusion}

Based on the result of the present study, it was concluded that:

- A statistically significant difference improvement was found between critical care nurses' knowledge in pre and post-implementing of the educational program regarding the care of patients with pulmonary embolism in the emergency stage.

- A statistically significant difference improvement was found between critical care nurses' practice in pre and post-implementing educational programs regarding the care of patients with pulmonary embolism in the emergency stage.

- There is a correlation found between knowledge and practice score obtained by critical care nurses receiving the educational program.

\section{Recommendations}

Based on the results of the present study the following be recommended:

- There must be standardized written nursing care of patients with pulmonary embolism in intensive care units and the department. In addition to provide nursing library and net including all different nursing sciences.

Replication of the study on a larger probability sample acquired from the different geographical areas in Yemen to figure out the main aspects of these problems.

\section{References}

1. AbdEInaeem, M., (2015): Effect of implementing cardiopulmonary resuscitation teaching program on knowledge and skills of critical care nurses at Assiut University Hospital. Assiut University.

2. Abdul-hamza, M., \& Aziz, A., (2017): Effectiveness of an Educational Program upon Nurses ' Knowledge toward the Continuous Positive Airway Pressure Machine in Neonatal Intensive Care Unit at AL-Hussein and the 
Pediatric Teaching Hospital. International Journal of Science and Research, 6(10), 10-16. https://doi.org/10.21275/ART20177047

3. Al-husaunawy, A., (2015): Evaluation of Nurses Knowledge and Practical of Electrocardiogram Toward Adolescent Patient. IOSR Journal of Nursing and Health Science, $4(4), \quad 10-16 . \quad$ https://doi.org/10.9790/195904421016

4. AL-Jumaily, A., \& Khudur, K., (2019): Effectiveness of an Education Program on Nurses knowledge concerning in Nursing Management for patients with Third degree and bundle branch block in Kirkuk Teaching Hospitals. Mosul Journal of Nursing, 7(1), 719.

5. Ali, M., \& Hassan, H., (2016): Effectiveness of Nursing Educational Program on Nurses Knowledge toward Venous Thromboembolism at Ibn Alnafees Teaching Hospital Abstract: IOSR Journal of Nursing and Health Science, 5(5), 27-30. https://doi.org/10.9790/19590505022730

6. Antony, A., Moly, K., \& Dharan, D., (2016): Assessment of Knowledge and Self Reported Clinical Practice on Prevention of Deep Vein Thrombosis among Staff Nurses. Journal of Nursing and Health Science, 5(1), 18-24. https://doi.org/10.9790/1959-05171824

7. Burton, M., \& Ludwig, L., (2015): Fundamentals of Nursing Care Concepts, Connections, \& Skills. (T. Ciavarella, Ed.) (2nd ed.). United States of America: F. A. Davis Company.

8. Chen, Y., Wang, X., Deng, H., \& He, Y., (2018): Nurses ' objective knowledge regarding venous thromboembolism prophylaxis. Www.md-Journal.com, 97(14), 1-7.

9. Clement, I., (2015): Management of Nursing Services and Education. (N. Valecha, Ed.) (2nd ed.). india: Reed Elsevier Inndia Pvt. Ltd.

10. Das, P., \& Sahoo, A., (2014): Effectiveness of the Planned Teaching Program on Deep Vein Thrombosis among the Staff Nurses of selected hospital. IOSR Journal of Nursing and Health Science, 3(1), 48-51.

11. El-sayedead, D., Fouad Abdallah, K., Hegazi, M., \& Mohammed, S., (2016): Effect of Nursing Care Standards for Preventing Deep Vein Thrombosis among Patients Undergoing Hip Surgery on Nurses Performance and Patients Outcome. Journal of Nursing and Health Science, 5(4), 1-12. https://doi.org/10.9790/1959-0504XXXXX

12. El Enein, N., El Ghany, A., \& Zaghloul, A.,
(2012): Knowledge and performance among nurses before and after a training programme on patient falls. Open Journal of Nursing, (2), 358364.

13. Eskander, H., Youssef, W., Morsy, M., Ali, H., \& Elfeky, A., (2013): Intensive Care Nurses 'Knowledge \& Practices regarding Infection Control Standard Precautions at a Selected Egyptian Cancer Hospital. Journal of Education and Practice, 4(19), 160-174.

14. Gaston, S., (2013): Venous thromboembolism risk assessment: Rural nurses' knowledge and use in a rural acute care hospital. International Journal of Nursing Practice, 60-64. https://doi.org/10.1111/ijn.12028

15. Hammod, H., \& Mohammed, S., (2016): Effectiveness of an Educational Program on Nurses Knowledge Concerning Complications Prevention of Mechanical Ventilation at Intensive Care Unit in Al- Hussain Teaching Hospital at Nassiryah City. Kufa Journal For Nursing Sciences, 6(2), 1-11.

16. Hassan, S., \& Hassan, H., (2013): Effectiveness of Nursing Education Program on Nurses Practices Toward Arrhythmia in Kirkuk $\hat{a} €^{\mathrm{TM}}$ s Teaching Hospitals. Kufa Journal for Nursing Sciences, 3(1), 220-230.

17. Hinkle, J., \& Cheever, K., (2017): Brunner \& Suddarth's textbook of medical-surgical nursing. (H. Surrena, Ed.) (14th ed.). China: Woliers Kiuwer / Lippincott Williams \& Wilkins.

18. Huisman, M., Barco, S., Cannegieter, S., Gal, G., Le, Konstantinides, S., Reitsma, P., Klok, F., (2018): Pulmonary embolism. DISEASE PRIMERS, 4(18028), 1-18. https://doi.org/10.1038/nrdp.2018.28

19. Jagannathan, P., (2015): Assess the Effectiveness of Structured Teaching Programme on Knowledge Regarding Prophylactic Measures in Prevention of Deep Vein Thrombosis Among Patients Confined To. International Journal of Scientific Research, 4(8), 3-5.

20. Jaralnabi, A., Atawi, S., \& Sagiron, W., (2017): Effect of Education Program on Nurses ' Knowledge, Attitude, and Intentions Towards Myocardial Infarction Prevention and Treatment. American Journal of Environmental and Occupational Health, 2(2), 7-9.

21. Karaaslan, M., Celik, A., Cagliyan, C., \& Demir, M., (2018): Thrombus in Transit Causing Acute Massive Pulmonary Emboli Treated Successfully with Reteplase 
Administration. International Journal of the Cardiovascular Academy, 4(2), 35-36. https://doi.org/10.4103/IJCA.IJCA

22. Kaur, A., \& Charan, G., (2018): A Study to Assess the Effectiveness of STP on Knowledge and Practice Regarding ABGs among ICU Nurses in Selected Hospitals at Jalandhar, Punjab. International Journal of Health Sciences and Research, 8(8), 182-188.

23. Khalil, N., (2018): Critical care nurses use of non-pharmacological pain management methods in Egypt. Applied Nursing Research, 44, 33-38. https://doi.org/10.1016/j.apnr.2018.09.001.

24. Khalil, N., Rahman, H., \& Hamouda, E., Yaser, (2018): Critical care nurses â€ $€^{\mathrm{TM}}$ knowledge and practice regarding lifethreatening ventricular dysrhythmias. ClinicalPractice, 15(4), 747-753.

25. Lee, J., Grochow, D., Drake, D., Johnson, L., Reed, P., \& Servellen, G., Van, (2014): Evaluation of hospital nurses ', perceived knowledge and practices of venous thromboembolism assessment and prevention. Journal of Vascular Nursing, 32(1), 18-24. https://doi.org/10.1016/j.jvn.2013.06.001

26. Mitoma, R., \& Yamauchi, T., (2018): Effect of a physical assessment educational program on clinical practice. Journal of Nursing Education and Practice, 8(8). https://doi.org/10.5430/jnep.v8n8p96

27. Mohammed, A., Hassan, A., Mohamed, M., \& Rn, A., (2018): Effect of Educational Program on Nurses â $€^{\mathrm{TM}}$ practice Regarding Care of Adult Patients with Endotracheal Tube. Port Said Scientific Journal of Nursing, 5(2), 253-280.

28. Mohammed, W., (2017): Outcomes of implaminting a clinical pathway for servere traumatic brain injury. Assiut University.

29. Morrone, D., \& Morrone, V., (2018): Acute Pulmonary Embolism: Focus on the Clinical Picture. Korean Circulation Journal, 48(5), 365381.

30. Morton, P., \& Fontaine, D., (2017): Critical care nursing: a holistic approach. (C. Richardson, Ed.) (11th ed.). China: Lippincott Williams \& Wilkins.

31. Sage, S., Le, Mcgee, M., Candidate, A., \& Emed, J., (2008): Knowledge of Venous Thromboembolism prevention among hospitalized patients. Journal of Vascular Nursing, XXVI(4), 109-117. https://doi.org/10.1016/j.jvn.2008.09.005

32. Shehab, M., (2018): Impact of an Educational Program on Nurses â€ $€^{\mathrm{TM}}$ Knowledge and
Practice Regarding Care of Traumatic Brain I njury Patients at Intensive Care Unit at Suez Canal University Hospital.

International Journal of Caring Sciences, 11(2), 1104-1116.

33. Wilkinson, J., Treas, L., Barnett, K., \& Smith, M., (2016): Fundamentals of nursing. (S. A. Kuhn, Ed.) (3rd ed.). United States of America: F. A. Davis Company. 